\title{
The hydrogen chemistry of the FeMo-co active site of nitrogenase
}

\author{
Ian Dance
}

School of Chemistry, University of New South Wales, Sydney 2052, Australia

Email: I.Dance@unsw.edu.au

\section{Contents}

- Results assessing the accuracy of the density functional methodology.

- Reaction profiles for H-transfer reactions.

- Structures with more than one $\mathrm{H}$ atom

- Isomers for $\mathrm{H}_{2}$ bound to $\mathrm{Fe} 2$ or $\mathrm{Fe} 6$

- Reaction profiles for the formation of $\mathrm{H}_{2}$

- $\mathrm{Fe}(\mathrm{H})_{2} \Leftrightarrow \mathrm{Fe}\left(\mathrm{H}_{2}\right)$ interconversion

- Structures with $\mathrm{Fe}-\mathrm{H}_{2}$ and additional $\mathrm{H}$ atoms

- Association/dissociation profiles for $\mathrm{Fe}-\mathrm{H}_{2}$

- $\mathrm{H} / \mathrm{H}_{2}$ exchange

- Key principles for the coordination chemistry of hydrogenated FeMo-co.

- References 
Results assessing the accuracy of the density functional methodology

Table S1. Comparison of the observed interatomic distances $(\AA)$ of FeMo-co (crystal structure $1 \mathrm{M} 1 \mathrm{~N}$ ) with $\mathrm{DF}$ calculated distances for an $\mathrm{S}=3 / 2$ state and for an $S=1 / 2$ state. Atom labels from $1 \mathrm{M} 1 \mathrm{~N}$.

\begin{tabular}{|c|c|c|c|}
\hline distance & $\begin{array}{c}\text { expt } \\
1 \mathrm{M} 1 \mathrm{~N}\end{array}$ & $\begin{array}{c}\text { DF calcd } \\
\mathrm{S}=3 / 2\end{array}$ & $\begin{array}{c}\text { DF calcd } \\
\mathrm{S}=1 / 2\end{array}$ \\
\hline \multicolumn{4}{|l|}{ Fe1 coord ${ }^{n}$} \\
\hline Fe1-SG & 2.258 & 2.287 & 2.256 \\
\hline Fe1-S1A & 2.273 & 2.284 & 2.251 \\
\hline $\mathrm{Fe} 1-\mathrm{S} 2 \mathrm{~A}$ & 2.259 & 2.281 & 2.236 \\
\hline Fe1-S4A & 2.273 & 2.269 & 2.224 \\
\hline mean & 2.266 & 2.280 & 2.242 \\
\hline \multicolumn{4}{|c|}{ upper Fe- $\left(\mu_{3}-S\right)$} \\
\hline Fe2-S1A & 2.262 & 2.340 & 2.343 \\
\hline Fe2-S2A & 2.247 & 2.330 & 2.353 \\
\hline $\mathrm{Fe} 3-\mathrm{S} 2 \mathrm{~A}$ & 2.259 & 2.324 & 2.341 \\
\hline Fe3-S4A & 2.273 & 2.328 & 2.329 \\
\hline $\mathrm{Fe} 4-\mathrm{S} 4 \mathrm{~A}$ & 2.291 & 2.332 & 2.352 \\
\hline $\mathrm{Fe} 4-\mathrm{S} 1 \mathrm{~A}$ & 2.281 & 2.311 & 2.336 \\
\hline mean & 2.276 & 2.324 & 2.340 \\
\hline \multicolumn{4}{|c|}{ lower $\mathrm{Fe}-\left(\mu_{3}-\mathrm{S}\right)$} \\
\hline Fe6-S3B & 2.218 & 2.297 & 2.305 \\
\hline $\mathrm{Fe} 7-\mathrm{S} 3 \mathrm{~B}$ & 2.258 & 2.316 & 2.313 \\
\hline Fe7-S4B & 2.212 & 2.303 & 2.296 \\
\hline Fe5-S4B & 2.243 & 2.304 & 2.323 \\
\hline Fe5-S1B & 2.264 & 2.285 & 2.319 \\
\hline Fe6-S1B & 2.230 & 2.300 & 2.290 \\
\hline mean & 2.237 & 2.298 & 2.307 \\
\hline \multicolumn{4}{|l|}{$\mathrm{Fe}-(\mu-\mathrm{S})$} \\
\hline Fe2-S2B & 2.206 & 2.236 & 2.245 \\
\hline Fe3-S5A & 2.214 & 2.248 & 2.235 \\
\hline $\mathrm{Fe} 4-\mathrm{S} 3 \mathrm{~A}$ & 2.242 & 2.237 & 2.239 \\
\hline Fe6-S2B & 2.165 & 2.249 & 2.244 \\
\hline Fe7-S5A & 2.207 & 2.230 & 2.247 \\
\hline Fe5-S3A & 2.252 & 2.246 & 2.248 \\
\hline mean & 2.217 & 2.241 & 2.245 \\
\hline \multicolumn{4}{|l|}{ Mo- $\left(\mu_{3}-S\right)$} \\
\hline Mo1-S1B & 2.340 & 2.440 & 2.435 \\
\hline Mo1-S3B & 2.366 & 2.402 & 2.398 \\
\hline Mo1-S4B & 2.331 & 2.450 & 2.452 \\
\hline
\end{tabular}




\begin{tabular}{|c|c|c|c|}
\hline mean & 2.346 & 2.431 & 2.428 \\
\hline \multicolumn{4}{|l|}{$\mathrm{Fe}-\mathrm{N}^{\mathrm{c}}$} \\
\hline $\mathrm{Fe} 2-\mathrm{Nc}^{\mathrm{c}}$ & 2.026 & 2.015 & 2.053 \\
\hline $\mathrm{Fe} 3-\mathrm{N}^{\mathrm{c}}$ & 1.990 & 2.019 & 2.047 \\
\hline $\mathrm{Fe} 4-\mathrm{Nc}^{\mathrm{c}}$ & 1.924 & 1.977 & 1.993 \\
\hline $\mathrm{Fe} 6-\mathrm{N}^{\mathrm{c}}$ & 2.069 & 2.031 & 2.069 \\
\hline $\mathrm{Fe} 7-\mathrm{N}^{\mathrm{c}}$ & 2.033 & 2.083 & 2.068 \\
\hline $\mathrm{Fe} 5-\mathrm{N}^{\mathrm{c}}$ & 1.974 & 2.130 & 2.035 \\
\hline mean & 2.000 & 2.055 & 2.041 \\
\hline \multicolumn{4}{|c|}{ Fe-Fe prism edges } \\
\hline $\mathrm{Fe} 2-\mathrm{Fe} 6$ & 2.581 & 2.673 & 2.689 \\
\hline $\mathrm{Fe} 3-\mathrm{Fe} 7$ & 2.586 & 2.629 & 2.656 \\
\hline $\mathrm{Fe} 4-\mathrm{Fe} 5$ & 2.615 & 2.545 & 2.577 \\
\hline mean & 2.594 & 2.616 & 2.641 \\
\hline \multicolumn{4}{|c|}{ Fe-Fe triangle edges } \\
\hline $\mathrm{Fe} 2-\mathrm{Fe} 3$ & 2.673 & 2.725 & 2.666 \\
\hline $\mathrm{Fe} 3-\mathrm{Fe} 4$ & 2.644 & 2.748 & 2.743 \\
\hline $\mathrm{Fe} 2-\mathrm{Fe} 4$ & 2.653 & 2.724 & 2.693 \\
\hline Fe6-Fe7 & 2.605 & 2.715 & 2.695 \\
\hline $\mathrm{Fe} 5-\mathrm{Fe} 7$ & 2.623 & 2.738 & 2.703 \\
\hline $\mathrm{Fe} 5-\mathrm{Fe} 6$ & 2.638 & 2.640 & 2.717 \\
\hline mean & 2.630 & 2.704 & 2.702 \\
\hline \multicolumn{4}{|l|}{ Mo coord ${ }^{n}$} \\
\hline Mo1-O7 & 2.185 & 2.100 & 2.108 \\
\hline Mo1-O5 & 2.180 & 2.229 & 2.234 \\
\hline Mo1-ND1 & 2.304 & 2.493 & 2.494 \\
\hline
\end{tabular}

Summary (of the $S=3 / 2$ ) results. Calculated mean Fe-S distances in the various classes are 0.02 $0.06 \AA$ longer than the crystal structure; the calculated mean $\mathrm{Fe}-\mathrm{N}^{\mathrm{c}}$ distance is $0.05 \AA$ longer; the mean calculated Mo- $\left(\mu_{3}-\mathrm{S}\right)$ distance is $0.08 \AA$ longer; calculated mean Fe--Fe distances of the two types are 0.02 and $0.07 \AA$ longer than observed. 
$\mathrm{Fe}\left(\mathrm{H}_{2}\right)_{2}\left(\mathrm{H}_{2}\right)\left(\left(\mathrm{PEtPh}_{2}\right)_{3}{ }^{1}\right.$

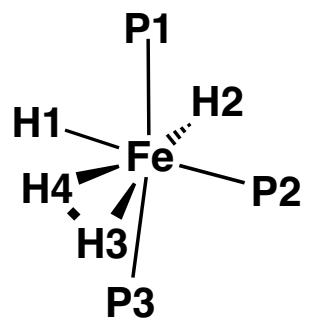

Table S2.

\begin{tabular}{|c:c|c|}
\hline & expt & DF calc \\
\hline Fe-H1 & 1.513 & 1.541 \\
\hline Fe-H2 & 1.539 & 1.543 \\
\hline Fe-H3 & 1.606 & 1.653 \\
\hline Fe-H4 & 1.576 & 1.638 \\
\hline H3-H4 & 0.820 & 0.846 \\
\hline Fe-P1 & 2.175 & 2.262 \\
\hline Fe-P2 & 2.206 & 2.330 \\
\hline Fe-P3 & 2.162 & 2.254 \\
\hline H1-Fe-H2 & 88.2 & 89.8 \\
\hline H1-Fe-H3 & 95.4 & 93.9 \\
\hline H1-Fe-H4 & 74.2 & 74.6 \\
\hline H2-Fe-H3 & 168.8 & 167.9 \\
\hline H2-Fe-H4 & 159.6 & 160.8 \\
\hline P1-Fe-P3 & 149.9 & 150.1 \\
\hline P2-Fe-H1 & 177.8 & 176.0 \\
\hline
\end{tabular}


$\operatorname{Fe}(\mathrm{H})_{2}\left(\boldsymbol{\eta}^{1}-\mathrm{N}_{2}\right)\left(\operatorname{PEtPh}_{2}\right)_{3}{ }^{1}$

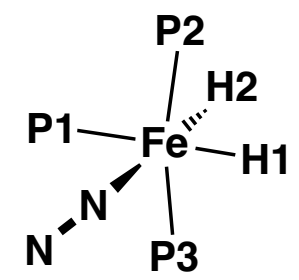

Table S3.

\begin{tabular}{|c|c|c|}
\hline & expt & DF calc \\
\hline Fe-P1 & 2.234 & 2.349 \\
\hline Fe-P2 & 2.222 & 2.339 \\
\hline Fe-P3 & 2.194 & 2.286 \\
\hline Fe-N & 1.846 & 1.838 \\
\hline Fe-H1 & 1.540 & 1.538 \\
\hline Fe-H2 & 1.544 & 1.552 \\
\hline $\mathrm{N}-\mathrm{N}$ & 1.138 & 1.135 \\
\hline $\mathrm{P} 1-\mathrm{Fe}-\mathrm{P} 2$ & 105.8 & 105.0 \\
\hline $\mathrm{P} 1-\mathrm{Fe}-\mathrm{P} 3$ & 104.2 & 104.7 \\
\hline $\mathrm{P} 1-\mathrm{Fe}-\mathrm{H} 1$ & 160.0 & 164.7 \\
\hline $\mathrm{P} 2-\mathrm{Fe}-\mathrm{P} 3$ & 149.3 & 149.4 \\
\hline $\mathrm{N}-\mathrm{Fe}-\mathrm{H} 1$ & 102.4 & 96.5 \\
\hline $\mathrm{N}-\mathrm{Fe}-\mathrm{H} 2$ & 176.3 & 179.0 \\
\hline $\mathrm{H} 1-\mathrm{Fe}-\mathrm{H} 2$ & 81.3 & 82.9 \\
\hline
\end{tabular}




\section{$\left[\mathrm{M}\left(\mathrm{PMe}_{3}\right)_{4} \mathrm{H}_{3}\right]^{+}$and $\left[\mathrm{M}\left(\mathrm{PMe}_{3}\right)_{4} \mathrm{H}\left(\mathrm{H}_{2}\right)\right]^{+}$}

Gusev et al ${ }^{2}$ describe the crystal structures of $\left[\mathrm{Fe}\left(\mathrm{PMe}_{3}\right)_{4} \mathrm{H}_{3}\right]^{+}[\mathrm{ROGBUK}],\left[\mathrm{Fe}\left(\mathrm{PEt}_{3}\right)_{4} \mathrm{H}_{3}\right]^{+}$ [ROGCAR] and $\left[\mathrm{Os}\left(\mathrm{PMe}_{3}\right)_{4} \mathrm{H}_{3}\right]^{+}[\mathrm{ROGCEV}]$ and the structures of these complexes in solution by NMR. There is isomerism between a seven-coordinate structure $\left[\mathrm{M}\left(\mathrm{PMe}_{3}\right)_{4} \mathrm{H}_{3}\right]^{+}$with threefold symmetry and a pseudo-tetrahedral array of phosphines (labelled the $\mathrm{T}$ isomer) and an octahedral $\left[\mathrm{M}\left(\mathrm{PMe}_{3}\right)_{4} \mathrm{H}\left(\mathrm{H}_{2}\right)\right]^{+}$(labelled the $\mathrm{C}_{\mathrm{n}}$ isomer). The enthalpy difference between $\left[\mathrm{Fe}\left(\mathrm{PMe}_{3}\right)_{4} \mathrm{H}_{3}\right]^{+}$ and $\left[\mathrm{Fe}\left(\mathrm{PMe}_{3}\right)_{4} \mathrm{H}\left(\mathrm{H}_{2}\right)\right]^{+}$was estimated to be almost zero in solution. These two structures have been optimised by my DF methods: both isomers are local minima, geometrically in agreement with the crystal structures (although the calculated Fe-P distances are ca $0.1 \AA$ longer, as above), and the potential energy difference between them is $5 \mathrm{kcal} \mathrm{mol}^{-1}$ (in favor of $\left[\mathrm{Fe}\left(\mathrm{PMe}_{3}\right)_{4} \mathrm{H}\left(\mathrm{H}_{2}\right)\right]^{+}$). 


\section{$\left[\mathrm{PhB}\left(\mathrm{CH}_{2} \mathrm{PPr}\right)_{3}\right] \mathrm{Fe}(\mathrm{H})\left(\mathrm{PMe}_{3}\right), \mathrm{S}=1$}

Daida and Peters ${ }^{3}$ characterised some trihydrides and monohydrides of $\mathrm{Fe}$ containing the tripodal ligand $\mathrm{PhB}\left(\mathrm{CH}_{2} \mathrm{PPr}\right)_{3}$. One of these, $\left[\mathrm{PhB}\left(\mathrm{CH}_{2} \mathrm{PPr}^{\mathrm{i}}\right)_{3}\right] \mathrm{Fe}(\mathrm{H})\left(\mathrm{PMe}_{3}\right)$, has $\mathrm{S}=1$, with the structure

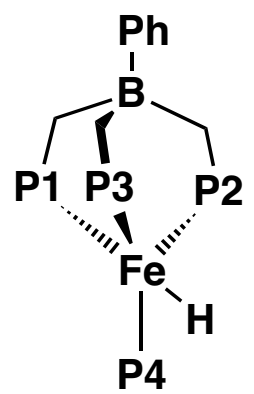

I have calculated the $\mathrm{S}=0$ and $\mathrm{S}=1$ states of this structure, and compared with the experimental crystal structure. The calculated $\mathrm{S}=1$ state gives a better account of the key P-Fe-P angles, italicised in Table S?.

Table S4.

\begin{tabular}{|c|c|c|c|}
\hline & expt & DFT, $=1$ & DFT, $\mathrm{S}=0$ \\
\hline Fe-H & 1.511 & 1.536 & 1.541 \\
\hline Fe-P1 & 2.314 & 2.415 & 2.416 \\
\hline Fe-P2 & 2.288 & 2.369 & 2.321 \\
\hline Fe-P3 & 2.308 & 2.408 & 2.344 \\
\hline Fe-P4 & 2.276 & 2.350 & 2.334 \\
\hline H-Fe-P4 & 66.3 & 73.2 & 70.3 \\
\hline P1-Fe-P2 & 95.1 & 95.0 & 93.3 \\
\hline P1-Fe-P3 & 95.1 & 94.4 & 90.2 \\
\hline$P 1-F e-P 4$ & 117.7 & 116.0 & 114.0 \\
\hline$P 2-F e-P 3$ & 96.4 & 97.9 & 92.4 \\
\hline$P 2-F e-P 4$ & 124.1 & 125.1 & 140.6 \\
\hline$P 3-F e-P 4$ & 121.6 & 121.6 & 114.3 \\
\hline
\end{tabular}




\section{$\left(\operatorname{PiPr}_{3}\right)_{2}(\mathbf{H})_{2} \operatorname{Ru}(\mu-H)_{3} \operatorname{Ru}(H)\left(\operatorname{PiPr}_{3}\right)_{2}$}

This unusual compound ${ }^{4}$ contains a triple bridge of $\mathrm{H}$ atoms, and terminal $\mathrm{H}$ atoms, on two different $\mathrm{Ru}$ atoms, one seven-coordinate, one six-coordinate. Table S? compares the experimental (refcode QINYAN) and calculated dimensions of the core. The calculated Ru-H distances track the experimental variations in the different types of $\mathrm{Ru}-\mathrm{H}$ bond.

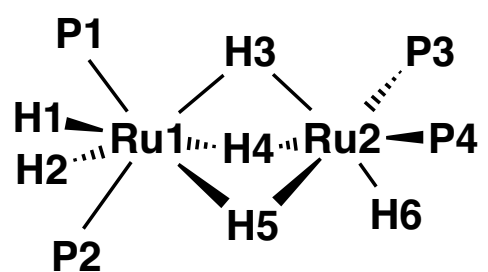

Table S5.

\begin{tabular}{|c|c|c|}
\hline & expt & DF calcd \\
\hline $\mathrm{Ru} 1-\mathrm{H} 4$ & 1.786 & 1.827 \\
\hline $\mathrm{Ru} 2-\mathrm{H} 4$ & 1.959 & 1.877 \\
\hline $\mathrm{Ru} 1-\mathrm{H} 3$ & 1.773 & 1.714 \\
\hline $\mathrm{Ru} 2-\mathrm{H} 3$ & 1.969 & 2.096 \\
\hline $\mathrm{Ru} 1-\mathrm{H} 5$ & 1.836 & 1.803 \\
\hline $\mathrm{Ru} 2-\mathrm{H} 5$ & 1.854 & 1.867 \\
\hline $\mathrm{Ru} 2-\mathrm{H} 6$ & 1.664 & 1.608 \\
\hline $\mathrm{Ru} 1-\mathrm{H} 1$ & 1.753 & 1.630 \\
\hline $\mathrm{Ru} 1-\mathrm{H} 2$ & 1.522 & 1.612 \\
\hline $\mathrm{Ru} 1-\mathrm{P} 2$ & 2.331 & 2.462 \\
\hline $\mathrm{Ru} 1-\mathrm{P} 1$ & 2.282 & 2.376 \\
\hline $\mathrm{Ru} 2-\mathrm{P} 3$ & 2.286 & 2.373 \\
\hline $\mathrm{Ru} 2-\mathrm{P} 4$ & 2.281 & 2.365 \\
\hline $\mathrm{Ru} 1-\mathrm{Ru} 2$ & 2.589 & 2.690 \\
\hline
\end{tabular}


Reaction profiles for $\mathrm{H}$-transfer reactions.

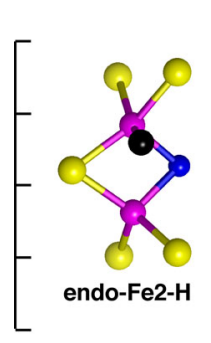

(-2)

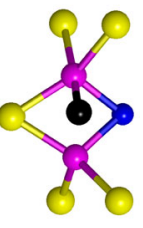

(+2)

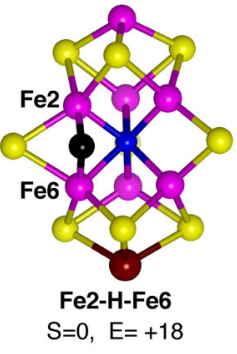

(0)

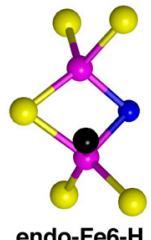

endo-Fe6-H

$(-1)$

Figure S1. The Fe2-H-Fe6 bridging structure (labelled, $\mathrm{E}=+18$ ), and the profile for transformation to the endo-Fe2-H or endo-Fe6-H structures (all S=0). Energies (kcal mol-1) encircled are relative, and the energy abscissa units are $5 \mathrm{kcal} \mathrm{mol}^{-1}$ : this convention is used in all following describing transformations. In the transition state (left) between endo-Fe2-H and Fe2-H-Fe6, the Fe-H distances differentiated by about $0.3 \AA$. The transition between Fe2-HFe6 and endo-Fe6-H on the right is so flat that the barrier could not be determined.
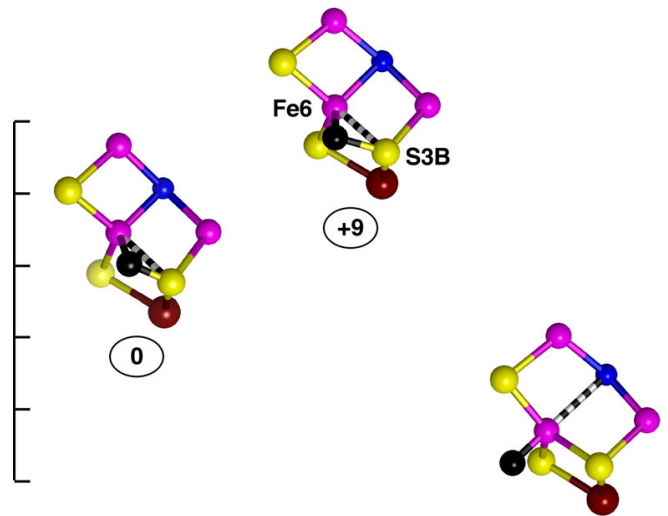

$(-13$

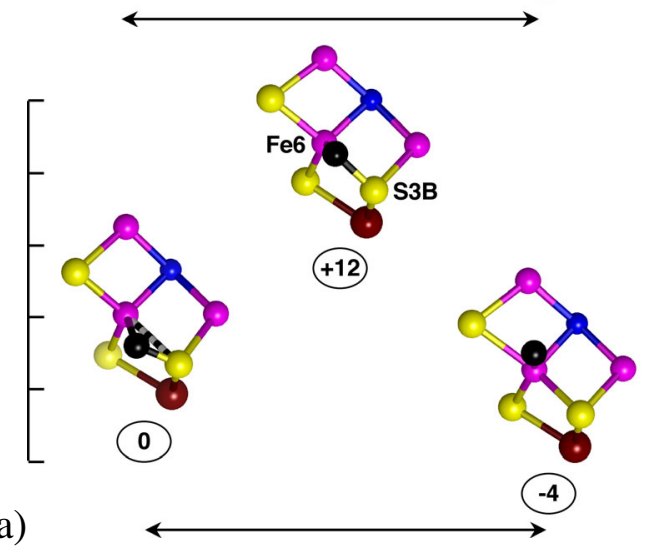

(b)

Figure S2. Reaction profiles for $\mathrm{H}$ transfer between $\mathrm{S} 3 \mathrm{~B}$ and $\mathrm{Fe} 6$ (all $\mathrm{S}=0$ ). (a) The transition state between S3BH-2 and exo-Fe6-H, with a forward barrier of $9 \mathrm{kcal} \mathrm{mol}^{-1}$. The progression

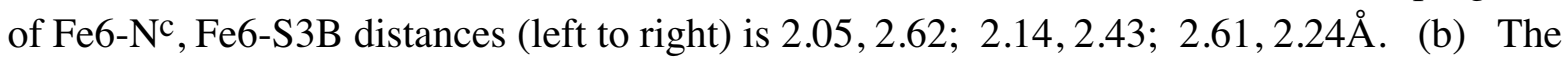
transition state between S3BH-2 and endo-Fe6-H. 


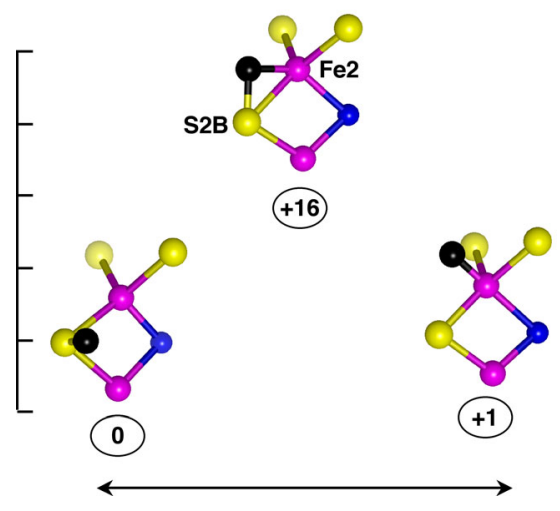

(a)

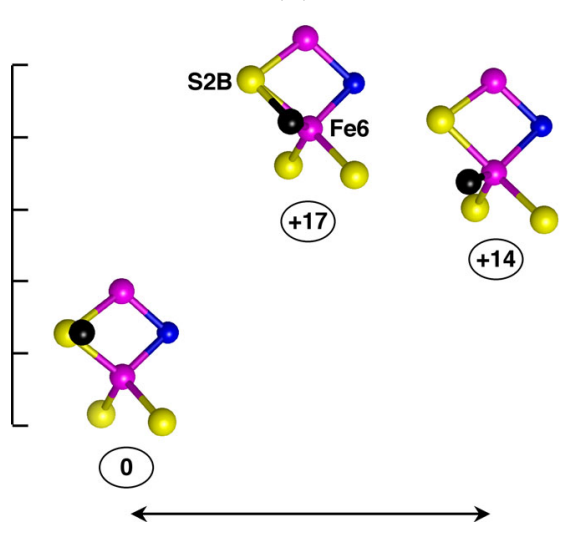

(b)

Figure S3. Reaction profiles for $\mathrm{H}$ transfer between $\mathrm{S} 2 \mathrm{~B}$ and $\mathrm{Fe}(\mathrm{S}=0)$. (a) The transfer between S2BH-1 and exo-Fe2-H. The transition state has $\mathrm{H}$ moved substantially away from the normal pyramidal stereochemistry at $\mathrm{S} 2 \mathrm{~B}$, causing a large barrier of $14 \mathrm{kcal} \mathrm{mol}^{-1}$ for a process that is endergonic by $1 \mathrm{kcal} \mathrm{mol}^{-1}$. (b) The transfer between S2BH-1 and endo-Fe6-H. Appreciable change in the S2B-Fe6-S3B angle is involved, which contributes to the barrier to 17 $\mathrm{kcal} \mathrm{mol}^{-1}$ : there is more uncertainty in the location of this transition state. 
Structures with more than one $\mathrm{H}$ atom

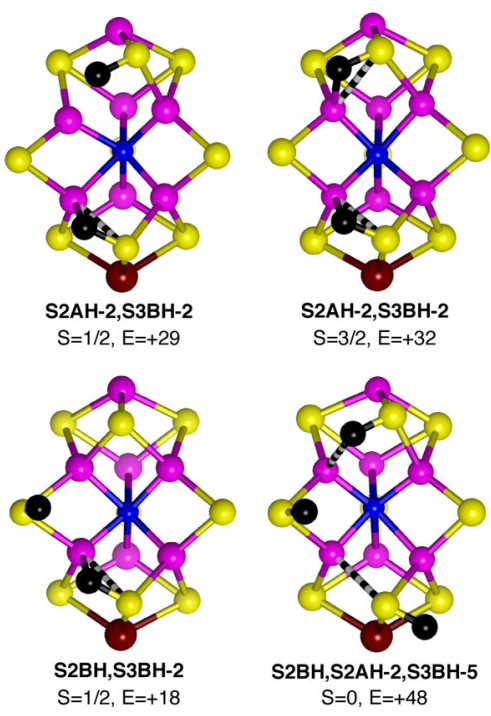

(a)
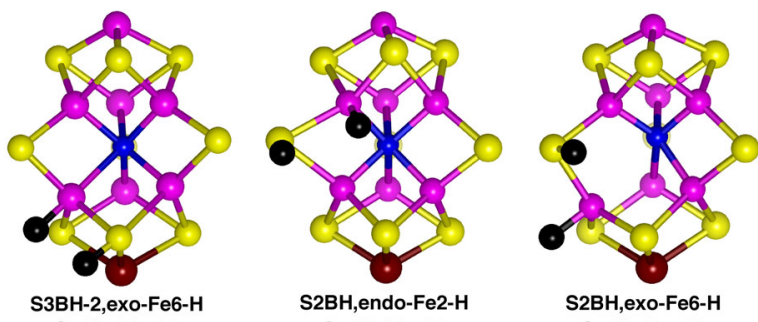

S $=1 / 2$, exo-Fe6-H

S=1/2,

$S=1 / 2, E=+20$
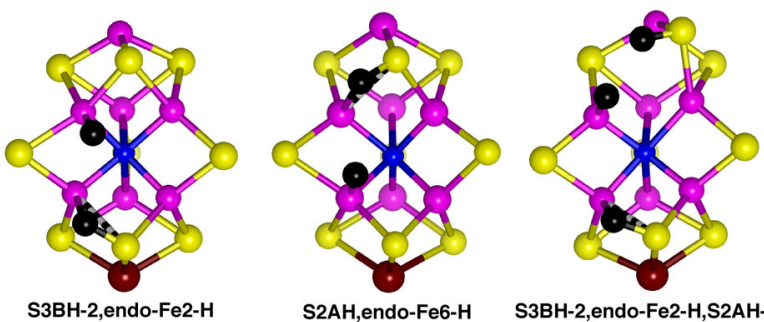

S2AH,endo-Fe6-H

S3BH-2,endo-Fe2-H,S2AH-2
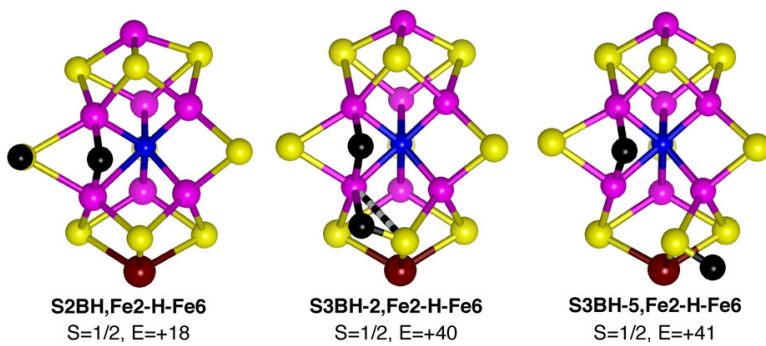

$\mathrm{S}=1 / 2, \mathrm{E}=+18$

$\mathrm{S}=1 / 2, \mathrm{E}=+40$

$S=1 / 2, E=+41$

(b) 

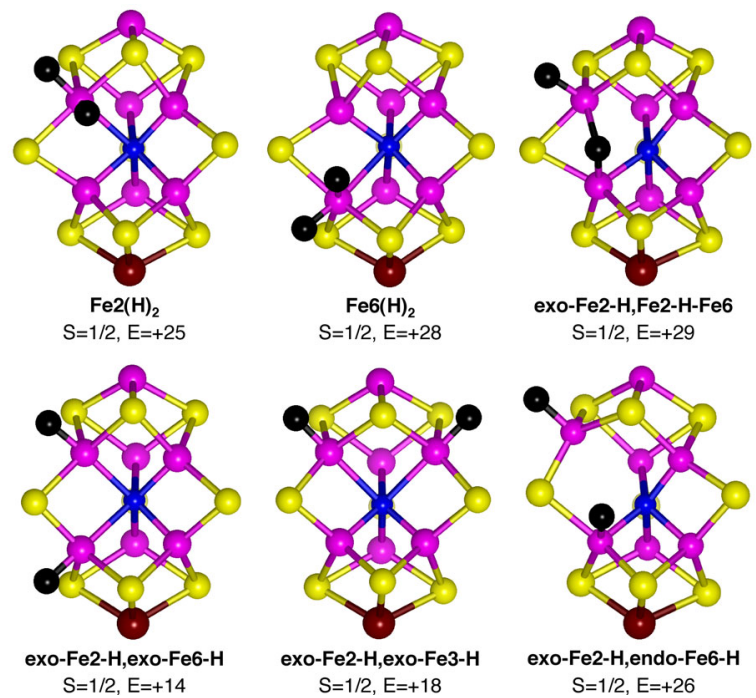

(c)
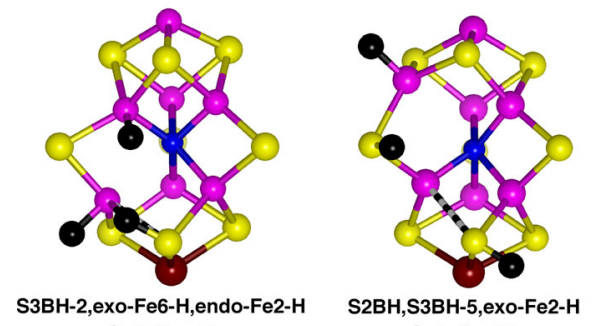

S3BH-2,exo-Fe6-H,endo-Fe2-H
\[ S=0, E=+49 \] $\mathrm{S}=0, \mathrm{E}=+35$

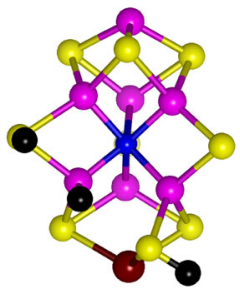

S2BH,S3BH-5,endo-Fe6-H $\mathrm{S}=0, \mathrm{E}=+28$

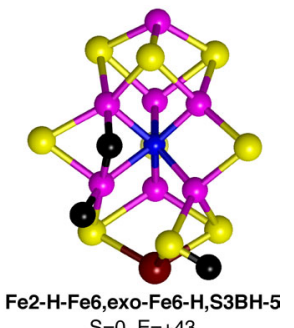

(d)

Figure S4. Structures containing two or three $\mathrm{H}$ atoms bound to $\mathrm{S}$ and/or Fe atoms of FeMo-co: $\mathrm{H}$ atoms are black, and extraneous atoms are omitted. Energies $\left(\mathrm{kcal} \mathrm{mol}^{-1}\right)$ for FeMo-co + $(\mathrm{H})_{n}$ are relative to $\left[\mathrm{E}(\mathbf{1})+\mathrm{n} / 2 \mathrm{E}\left(\mathrm{H}_{2}\right)\right]$. (a) Structures with SH only. (b) Structures with $\mathrm{SH}$ and $\mathrm{FeH}$. (c) Structures with FeH only. (d) Structures with $3 \mathrm{H}$. Elongated Fe-Nc distances $(\AA)$ are: $\mathrm{Fe}^{-\mathrm{N}^{\mathrm{c}}}=2.94$ in S2BH,exo-Fe6-H; Fe2-Nc = 3.11 in exo-Fe2-H,endo-Fe6-H; Fe2-Nc = 3.11 in S2BH,S3BH-5,exo-Fe2-H; Fe6-Nc = 2.67 in S3BH-2,exo-Fe6-H,endo-Fe2-H. 
Table S6. Isomers for $\mathrm{H}_{2}$ bound to Fe2 or Fe6.

\begin{tabular}{|c|c|c|c|c|c|}
\hline isomer & spin & $\begin{array}{c}\text { relative } \\
\text { energy } \\
\text { kcal mol-1 }^{-1}\end{array}$ & $\begin{array}{c}\mathrm{Fe}-\mathrm{N}^{\mathrm{c}} \\
\AA\end{array}$ & $\begin{array}{c}\mathrm{Fe}-\mathrm{H} \\
\AA\end{array}$ & $\begin{array}{c}\mathrm{H}-\mathrm{H} \\
\AA\end{array}$ \\
\hline \multicolumn{6}{|l|}{ exo-back-Fe2-H2 } \\
\hline $\mathbf{a}$ & $1 / 2$ & +11 & 2.16 & $1.72,1.73$ & 0.80 \\
\hline b & $3 / 2$ & +8 & 3.00 & $1.63,1.64$ & 0.84 \\
\hline \multicolumn{6}{|l|}{ exo-front-Fe2-H } \\
\hline $\mathbf{a}$ & $1 / 2$ & +7 & 2.19 & $1.70,1.70$ & 0.80 \\
\hline $\mathbf{b}$ & $3 / 2$ & +8 & 2.22 & $1.70,1.71$ & 0.81 \\
\hline c & $1 / 2$ & +13 & 3.00 & $1.62,1.63$ & 0.85 \\
\hline \multicolumn{6}{|l|}{ exo-back-Fe6-H } \\
\hline $\mathbf{a}$ & $1 / 2$ & +1 & 2.32 & $1.70,1.71$ & 0.80 \\
\hline $\mathbf{b}$ & $3 / 2$ & +6 & 2.40 & $1.67,1.68$ & 0.81 \\
\hline c & $1 / 2$ & +10 & 2.95 & $1.64,1.65$ & 0.83 \\
\hline \multicolumn{6}{|l|}{ exo-front-Fe6-H } \\
\hline $\mathbf{a}$ & $1 / 2$ & +6 & 2.18 & $1.84,1.85$ & 0.77 \\
\hline b & $1 / 2$ & +11 & 2.86 & $1.65,1.65$ & 0.82 \\
\hline \multicolumn{6}{|l|}{ endo-Fe2-H } \\
\hline & $3 / 2$ & +15 & 2.03 & $1.77,1.82$ & 0.79 \\
\hline \multicolumn{6}{|l|}{ endo-Fe6-H } \\
\hline $\mathbf{a}$ & $1 / 2$ & +21 & 2.28 & $1.74,1.76$ & 0.80 \\
\hline $\mathbf{b}$ & $3 / 2$ & +18 & 2.30 & $1.68,1.70$ & 0.82 \\
\hline c & $1 / 2$ & +20 & 2.62 & $1.68,1.69$ & 0.82 \\
\hline $\begin{array}{c}\text { endo-Fe6-H } \\
\text { parallel to } S 2 B--S 3 B\end{array}$ & $1 / 2$ & +21 & 2.48 & $1.73,1.76$ & 0.80 \\
\hline
\end{tabular}


Reaction profiles for the formation of $\mathrm{H}_{2}$
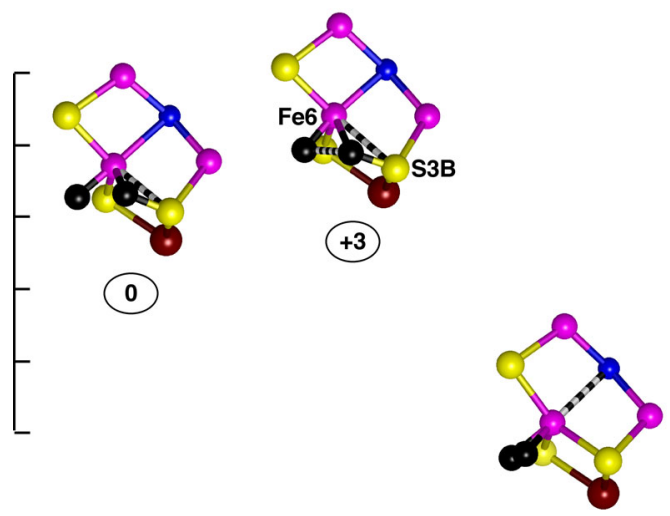

(-18)

(a)

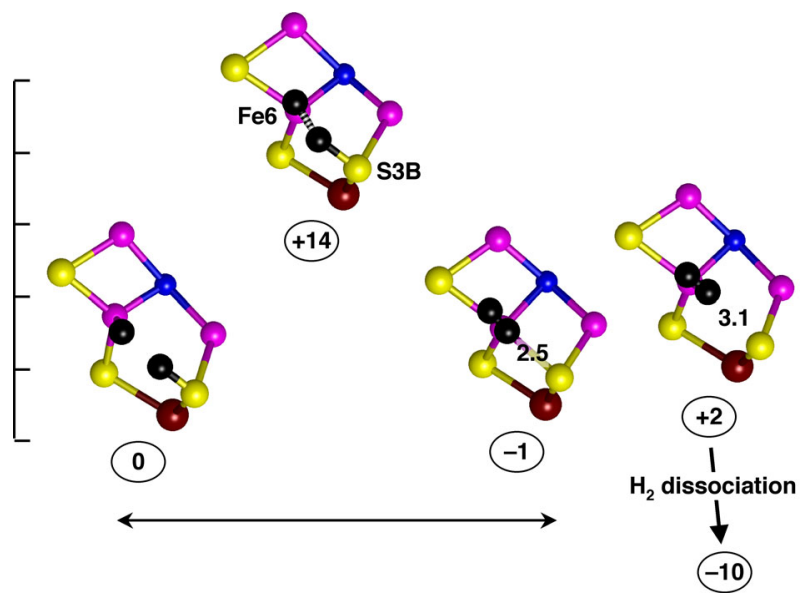

(b)

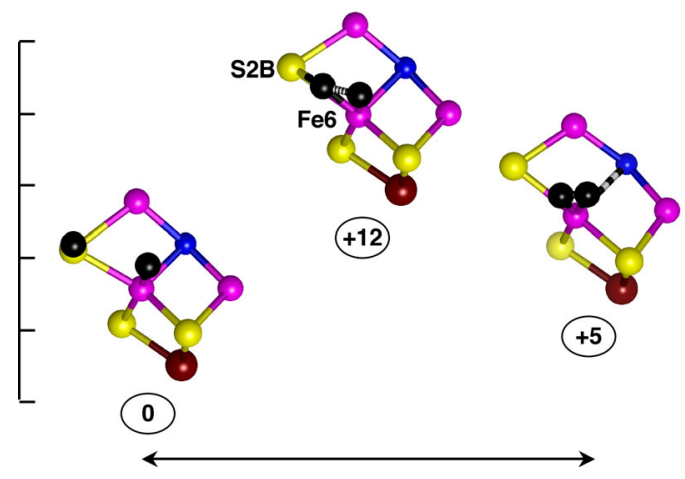

(c)

Figure S5. (a) Profile for formation of exo-Fe6- $\mathrm{H}_{2}$ by transfer from S3BH-2 to exo-Fe6-H $(\mathrm{S}=1 / 2)$. In the transition state $\mathrm{H}-\mathrm{H}=1.63 \AA$, Fe6-S3B $=2.78, \mathrm{Fe} 6-\mathrm{N}^{\mathrm{c}}=2.23 \AA$. Completion of the reaction involves $\mathrm{H}_{2}$ twisting to the back conformation. (b) Reaction profile for the formation of $\mathrm{H}_{2}$ by transfer from S3BH-2 to endo-Fe6-H $(\mathrm{S}=1 / 2)$. At the transition state the H$\mathrm{H}$ separation is $1.3 \AA$, and thereafter two energetically close pathways have been observed. If the Fe6-S3B shortens, $\mathrm{H}_{2}$ is formed bound to $\mathrm{Fe} 6$, as shown, and then twists from the parallel to transverse conformation (not shown). Alternatively, when Fe6-S3B stays long, $\mathrm{H}_{2}$ is formed on Fe6, but subsequently dissociates. In both cases the overall formation of $\mathrm{H}_{2}$ is exergonic. (c) 
Reaction profile for transfer of H from S2BH-1 to endo-Fe6-H $(\mathrm{S}=1 / 2)$ to generate endo-Fe6$\mathrm{H}_{2}$. In the transition state $\mathrm{H}-\mathrm{H}=1.17 \AA$. 
$\mathrm{Fe}(\mathrm{H})_{2} \Leftrightarrow \mathrm{Fe}\left(\mathrm{H}_{2}\right)$ interconversion
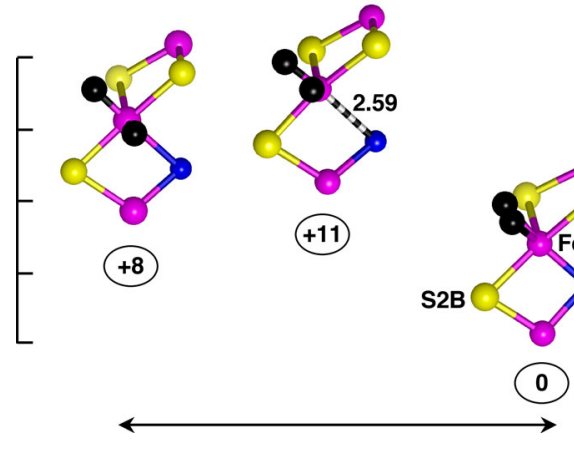

(a

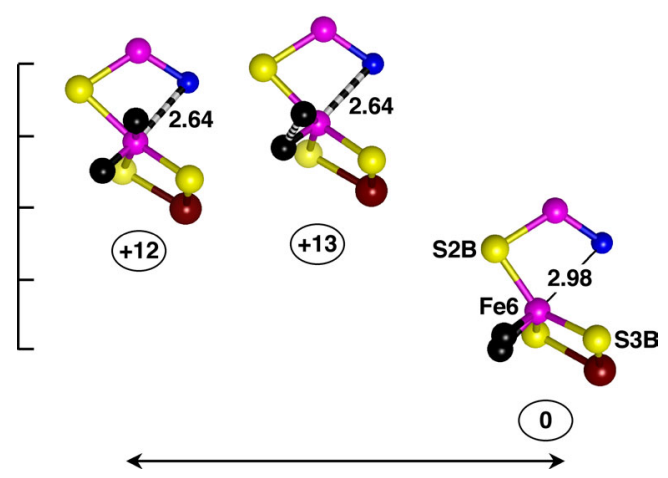

(b)

Figure S6. Profiles for the $\mathrm{Fe}(\mathrm{H})_{2} \Leftrightarrow \mathrm{Fe}\left(\mathrm{H}_{2}\right)$ interconversion, with energies (encircled) relative to the $\mathrm{Fe}-\mathrm{H}_{2}$ state. (a) At $\mathrm{Fe} 2$, involving short exo-Fe2- $\mathrm{H}_{2}, \mathrm{~S}=1 / 2 . \mathrm{H}-\mathrm{H}$ distances, left to right, are $1.95,1.33,0.78 \AA$ (b) At Fe6, involving long exo-Fe6- $\mathrm{H}_{2}, \mathrm{~S}=1 / 2$. H-H distances, left to right, are $1.91,1.34,0.83 \AA$. 
Structures with $\mathrm{Fe}-\mathrm{H}_{2}$ and additional $\mathrm{H}$ atoms
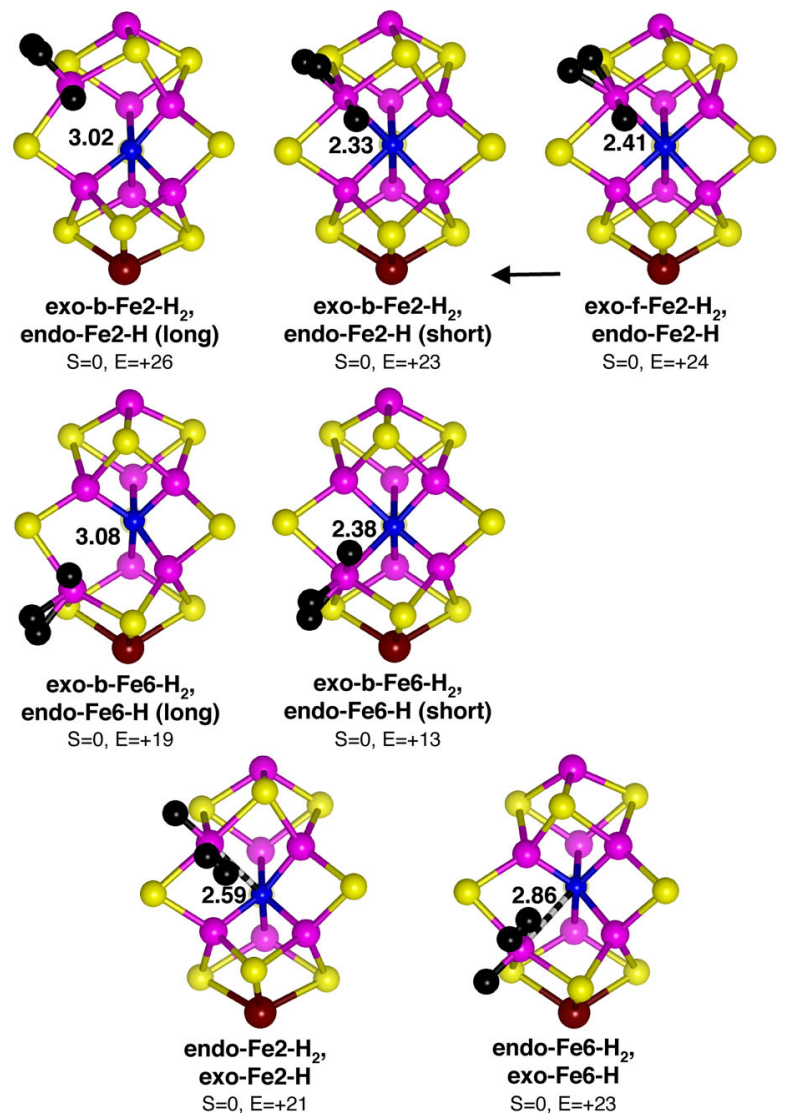

(a)
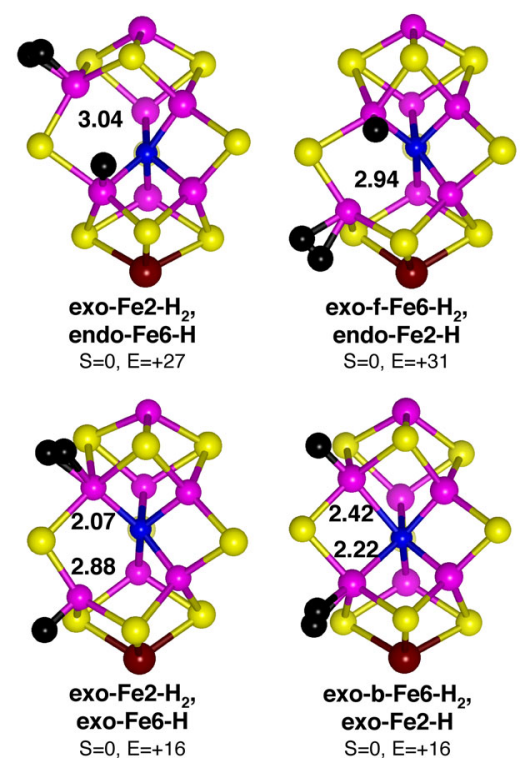

(b) 


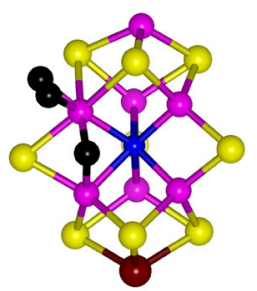

exo-b-Fe2- ${ }_{2}$, Fe2-H-Fe6 $\mathrm{S}=0, \mathrm{E}=+22$

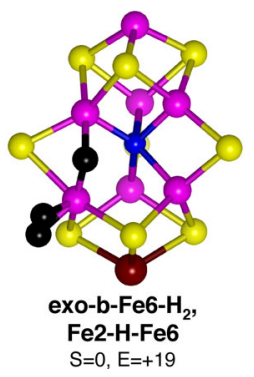

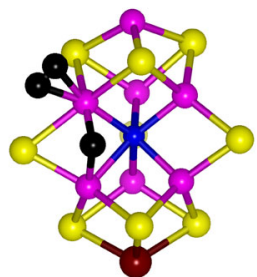

exo-f-Fe2- $\mathrm{H}_{2}$, Fe2-H-Fe6 $\mathrm{S}=0, \mathrm{E}=+27$

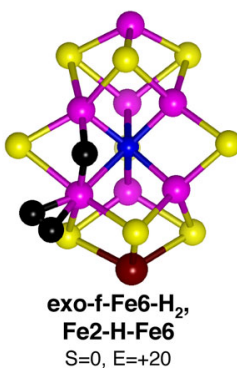

(c)

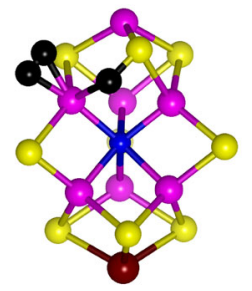

exo-Fe2- $\mathrm{H}_{2}, \mathrm{~S} 2 \mathrm{AH}-2$

$\mathrm{S}=0, \mathrm{E}=+30$

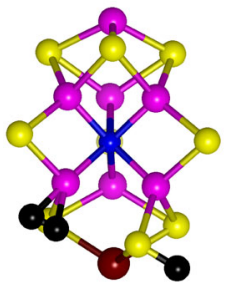

exo-Fe6- $\mathrm{H}_{2}, \mathrm{~S} 3 \mathrm{BH}-5$ $\mathrm{S}=0, \mathrm{E}=+27$

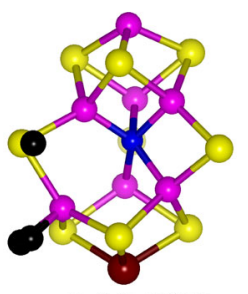

exo-Fe6- $\mathrm{H}_{2}, \mathrm{~S} 2 \mathrm{BH}$

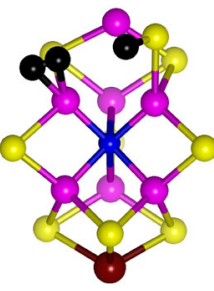

exo-Fe2- $\mathrm{H}_{2}, \mathrm{~S} 2 \mathrm{AH}-2$ $\mathrm{S}=0, \mathrm{E}=+20$

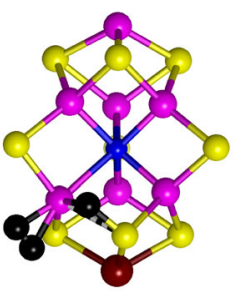

exo-Fe6- $\mathrm{H}_{2}, \mathrm{~S} 3 \mathrm{BH}-2$ $S=0, E=+26$

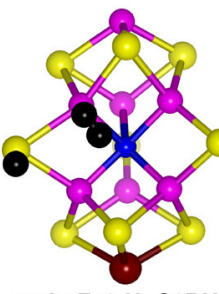

endo-Fe2- $\mathrm{H}_{2}, \mathrm{~S} 2 \mathrm{BH}$

(d)

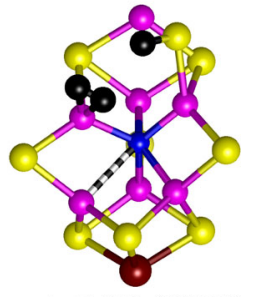

endo-Fe2- $\mathrm{H}_{2}, \mathrm{~S} 2 \mathrm{AH}-2$

$S=0, E=+24$

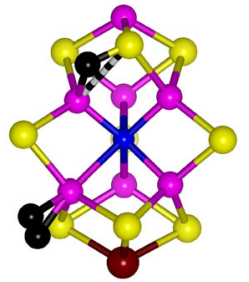

exo-Fe6- ${ }_{2}, \mathrm{~S} 2 \mathrm{AH}-2$

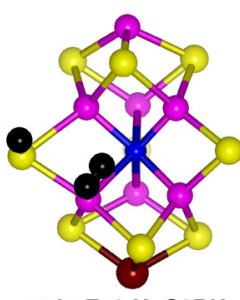

endo-Fe6- $\mathrm{H}_{2}, \mathrm{~S} 2 \mathrm{BH}$ $\mathrm{S}=0, \mathrm{E}=+19$ 

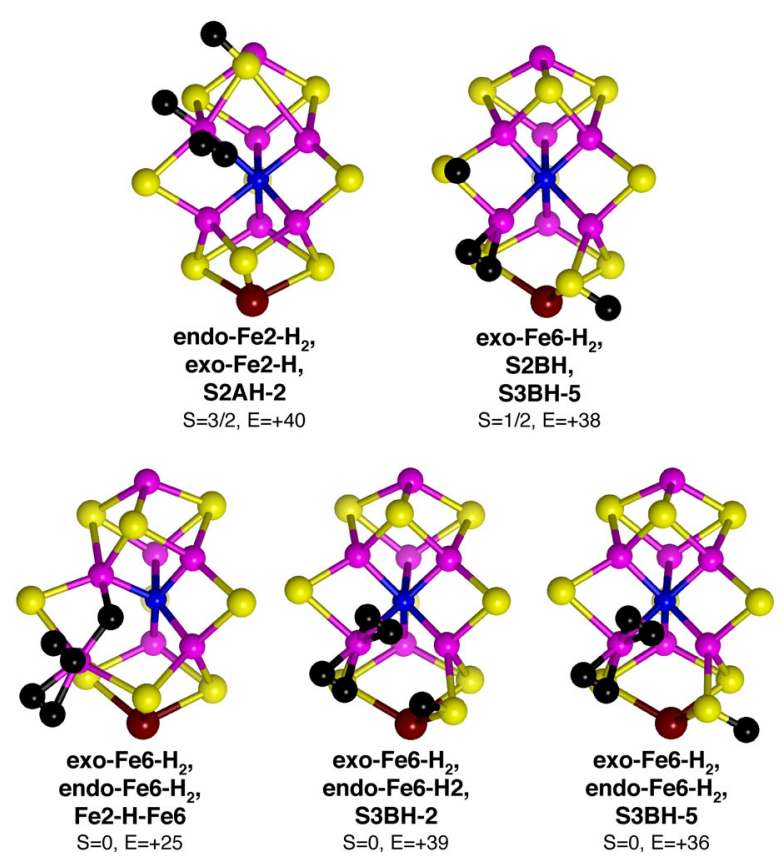

(e)

Figure S7. Optimised structures and isomers with $\mathrm{H}_{2}$ bound to hydrogenated FeMo-co. The labels $\mathrm{f}$ and $\mathrm{b}$ describe the alignment of $\mathrm{H}_{2}$ front or back, as defined in Fig 14, and relative energies $\mathrm{E}$ are in $\mathrm{kcal} \mathrm{mol}^{-1}$. Relevant $\mathrm{Fe}-\mathrm{N}^{\mathrm{c}}$ distances are marked. (a) Structures with $\mathrm{H}_{2}$ and $\mathrm{H}$ bound to the same $\mathrm{Fe}$ atom. The arrow indicates the barrierless conversion of front-exo-Fe2$\mathrm{H}_{2}$ conformer to the back conformer, with small energy advantage. (b) Structures with $\mathrm{H}_{2}$ and $\mathrm{H}$ bound to different $\mathrm{Fe}$ atoms on a prism edge of the $\mathrm{Fe}_{6}$ core. Note the geometrical difference between the equi-ergonic $\mathrm{Fe} 2$ and $\mathrm{Fe} 6$ analogs where both $\mathrm{H}_{2}$ and $\mathrm{H}$ are exo. (c) Optimised structures where there is an $\mathrm{Fe} 2-\mathrm{H}-\mathrm{Fe} 6$ bridge combined with exo-Fe- $\mathrm{H}_{2}$ in both front and back twist conformations. The Fe2-H-Fe6 bridge in these structures can be symmetrical with similar $\mathrm{Fe}-\mathrm{N}^{\mathrm{c}}$ distances (exo-b-Fe2-H, Fe2-H-Fe6, Fe2-Nc= 2.14, Fe6- $\mathrm{N}^{\mathrm{c}}=2.16 \AA$ ), or slewed with one

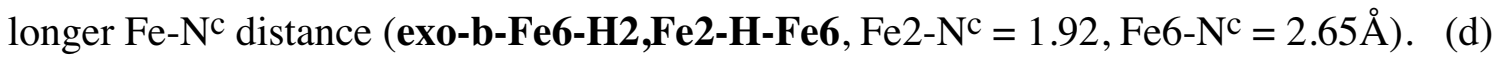
Optimised structures for $\mathrm{H}_{2}$ bound to $\mathrm{Fe}$ and $\mathrm{H}$ bound to $\mathrm{S}$. (e) Some optimised structures for FeMo-co binding four or five $\mathrm{H}$ atoms, including one or two $\mathrm{H}_{2}$ molecules. 


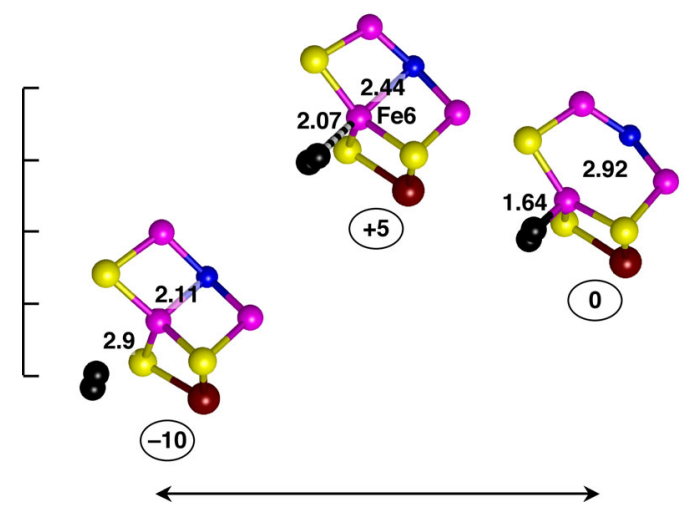

(a)

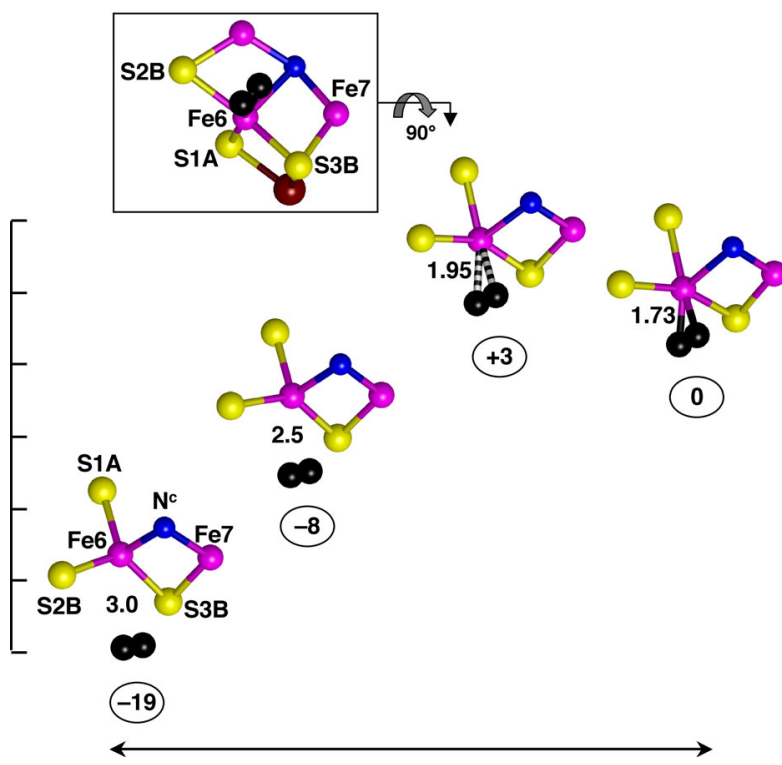

(b)

Figure S8. Reaction profiles for association/dissociation of $\mathrm{H}_{2}$ at $\mathrm{Fe} 6$, drawn on same energy abscissa as previous and following reaction profiles: $\mathrm{S}=1 / 2$ throughout. (a) Exo-Fe6- $\mathrm{H}_{2}$ coordination, in the standard view, showing only the immediate atoms. The progression of Fe6$\mathrm{H}$ and Fe6- $\mathrm{N}^{\mathrm{c}}$ distances is marked. (b) Endo-Fe6- $\mathrm{H}_{2}$ coordination, drawn looking down the Fe1--Mo axis, to emphasise the increase in S2B-Fe6-S3B angle required for association of $\mathrm{H}_{2}$, which is associated with a substantial portion of the total energy change. 

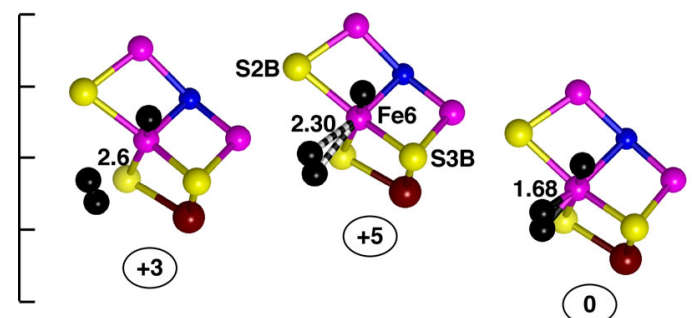

(0)

(a)
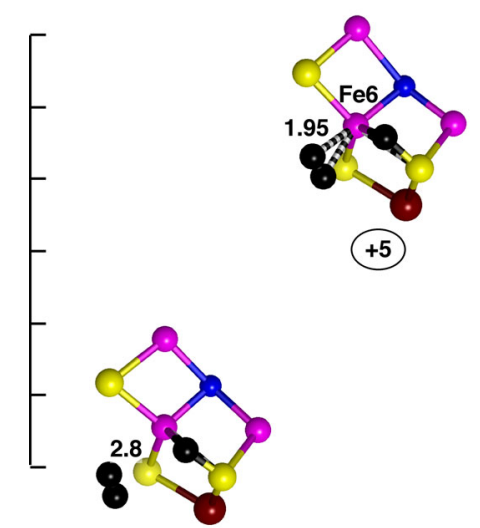

$+5$

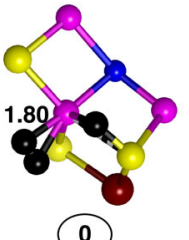

$-16$

(b)

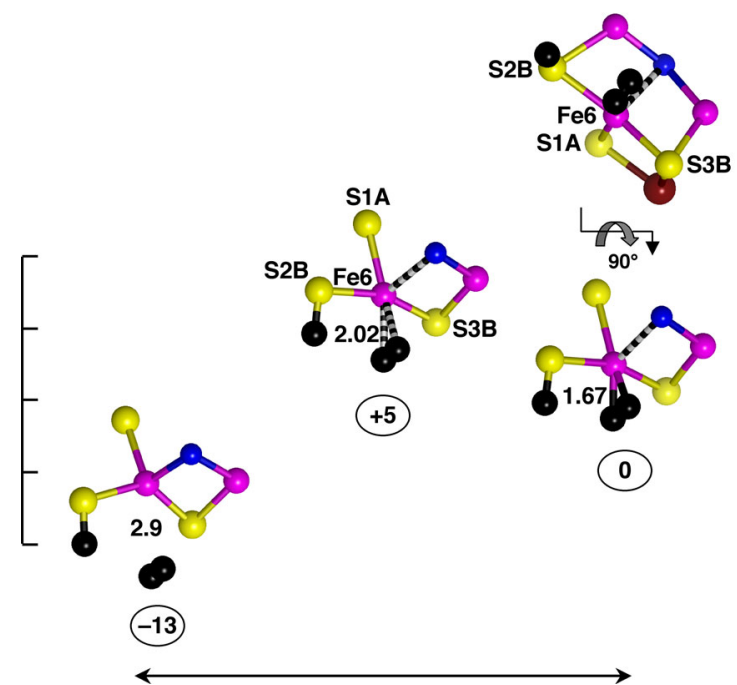

(c) 


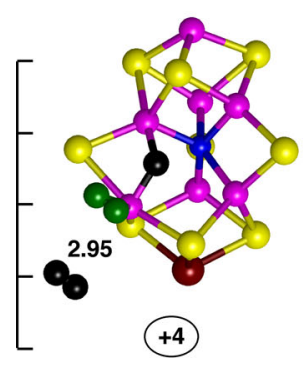

$+4$

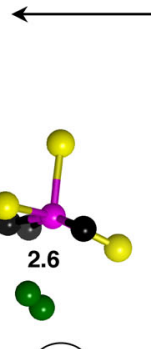

+13
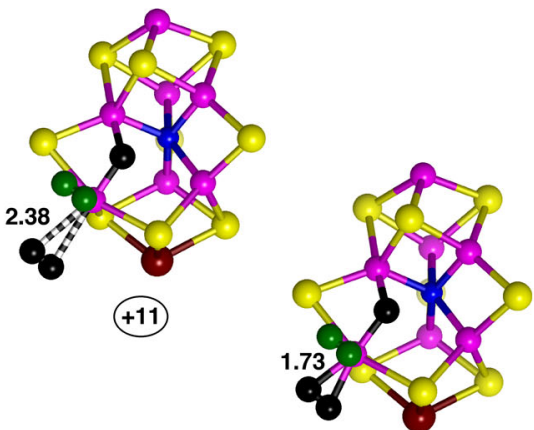

(0)

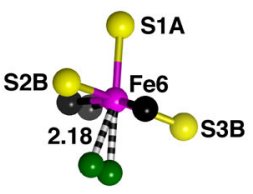

$+18$

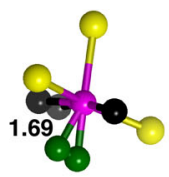

(0)

(d)

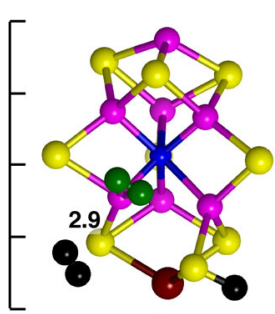

$+2$

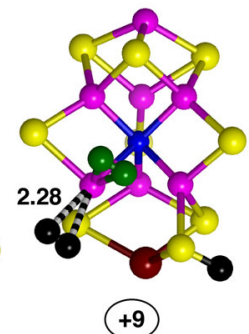

$+9$

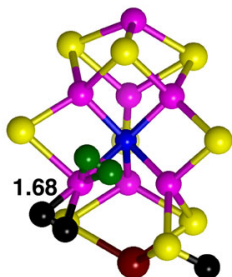

(0)

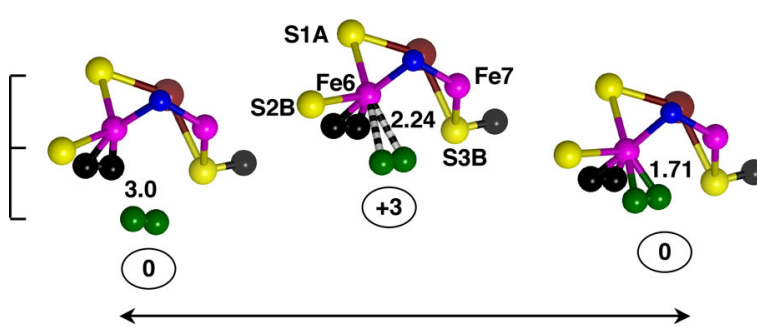

(e)

Figure S9. Reaction profiles for association/dissociation of $\mathrm{H}_{2}$ with FeMo-co with bound $\mathrm{H}$ atoms. Energies $\left(\mathrm{kcal} \mathrm{mol}^{-1}\right)$ relative to the associated state are encircled: the abscissa energy scale (5 kcal mol-1 divisions) is invariant and the same as Fig $11 . \mathrm{Fe}-\mathrm{H}\left(\mathrm{H}_{2}\right)$ distances $(\AA)$ are marked. (a) Profile for exo-b-Fe6-H dissociated side of the transition is remarkably flat, even for $\mathrm{Fe}-\mathrm{H}$ distances longer than the $2.6 \AA$ shown. The Fe6- $\mathrm{Nc}^{\mathrm{c}}$ distance is 2.17 in the transition state and $2.38 \AA$ in the associated state. (b) Profile for exo-Fe6- $\mathbf{H}_{2}, \mathbf{S 3 B H}-2(\mathrm{~S}=0)$ : the Fe6- $\mathrm{N}_{\mathrm{c}}$ distance is short throughout. (c) For 
endo-Fe6- $\mathrm{H}_{2}, \mathbf{S 2 B H}(\mathrm{S}=0)$, viewed from the top. The Fe6- $\mathrm{N}^{\mathrm{c}}$ distance changes through $2.12 \AA$ (dissociated), 2.55 (transition), 2.52A (associated). (d) Profiles for exo-Fe6- $\mathrm{H}_{2}$ (black, upper profile) and endo-Fe6- $\mathrm{H}_{2}$ (green, lower profile, viewed from above) in exo-Fe6- $\mathbf{H}_{2}$,endo-Fe6$\mathbf{H}_{2}, \mathbf{F e} 2-\mathrm{H}-\mathrm{Fe} 6$ : $\mathrm{S}=0$. (e) Profiles for exo-Fe6- $\mathrm{H}_{2}$ (black, upper profile) and endo-Fe6- $\mathrm{H}_{2}$ (green, lower profile, viewed from above) in exo-Fe6-H $\mathbf{H}_{2}$, endo-Fe6-H, $\mathbf{S 3 B H}-5$ : $\mathrm{S}=0$. 


\section{$\mathbf{H} / \mathrm{H}_{2}$ exchange}
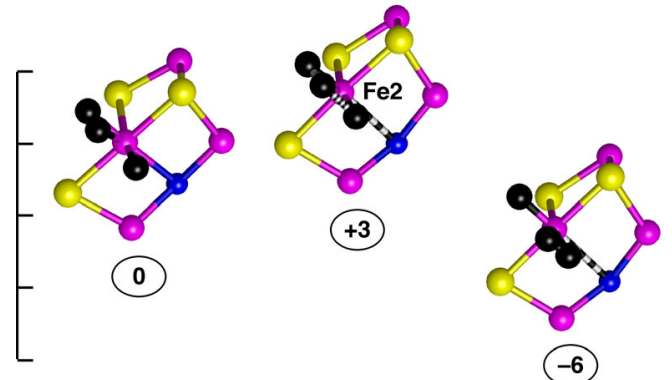

(-6)

(a)

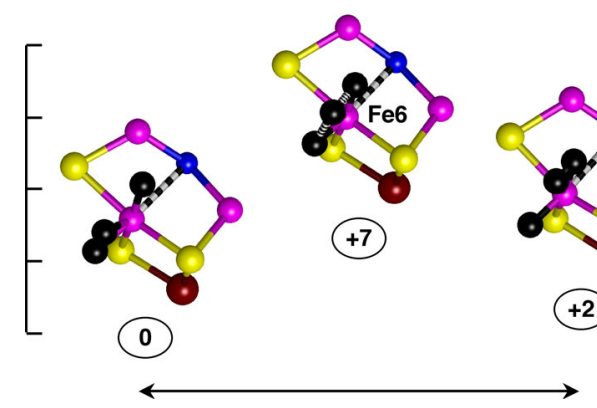

(b)

Figure S10. Profiles for interconversion of $\mathrm{H}_{2}$ and $\mathrm{H}$ at $\mathrm{Fe} 2$ and at $\mathrm{Fe} 6$ (all $\mathrm{S}=0$ ). $\mathrm{Fe} 2-\mathrm{N}^{\mathrm{c}}$ distances change from 2.4 to $2.7 \AA$, and Fe6-Nc distances vary 2.5 to $2.8 \AA$. 


\section{Key principles for the coordination chemistry of hydrogenated FeMo-co.}

(1) Electronation of FeMo-co increases the basicity of $\mu-\mathrm{S}$ and $\mu_{3}-\mathrm{S}$ atoms, which are the probable sites for initial protonation.

(2) $\mathrm{H}$ bound to $\mu$-S is more energetically favourable than $\mathrm{H}$ bound to $\mu_{3}-\mathrm{S}{ }^{5}$

(3) $\mathrm{H}$ atoms can move around $\mu_{3}-\mathrm{S}$ atoms, which have energetically soft stereochemistry.

(4) Protonation of $\mu_{3}$-S can weaken the bonds between this $\mathrm{S}$ atom and one of the three associated metal atoms, such that $\mu_{3}$-SH bonding approaches $\mu$-SH bonding. Usually $\mathrm{S}-\mathrm{Fe}$ bonds involving the central $\mathrm{Fe}$ atoms are elongated, possibly with complete severance. This $\mathrm{S}-\mathrm{Fe}$ distortion is different at the Mo and $\mathrm{Fe} 1$ ends of FeMo-co, and it appears that the less flexible angles at octahedral Mo, compared with tetrahedral Fe1, can cause the variations of S2AH and S3BH bonding at the two ends of FeMo-co to be different (see point 19 about other differences between the Fe and Mo ends of FeMo-co).

(5) Fe-H-S2A and Fe-H-S3B bridges are energetically favourable, and can be local minima.

(6) At the $\mu$-S atom, S2B-H has lesser geometrical flexibility, and Fe-H-S2B bridging is less likely than $\mathrm{Fe}-\mathrm{H}-\mathrm{S} 3 \mathrm{~B}$ or $\mathrm{Fe}-\mathrm{H}-\mathrm{S} 2 \mathrm{~A}$ bridging.

(7) Both Fe-H coordination and Fe- $\eta^{2}-\mathrm{H}_{2}$ coordination can occur in exo- and endo-coordination positions at the central $\mathrm{Fe}$ atoms, with exo-coordination energetically better. Endo coordination at Fe requires that the $\mu$-S atom (S2B) be folded away from the $\mathrm{Fe}_{4} \mathrm{~S}_{4}$ face, such that the $(\mu-\mathrm{S})-\mathrm{Fe}-$ $\left(\mu_{3}-\mathrm{S}\right)$ angle increases from ca 120 to $160^{\circ}$.

(8) Conformational twisting of exo- $\eta^{2}-\mathrm{H}_{2}$ around the $\mathrm{H}_{2}$-Fe centreline involves energy variations of $<2 \mathrm{kcal} \mathrm{mol}^{-1}$.

(9) For Fe coordinated by $\mathrm{H}$ and/or $\mathrm{H}_{2}$ there is significant isomerism according to the $\mathrm{Fe}-\mathrm{N}^{\mathrm{c}}$ distance, which can be 'short' (< ca 2.4 $\AA$ ) or 'long' (ca 2.6-3.1 $)$.

(10) The broad types of coordination for central Fe atoms are: trigonal bipyramidal (with exo ligation and short $\mathrm{Fe}-\mathrm{Nc}^{\mathrm{c}}$ ); square planar (with endo ligation and intermediate $\mathrm{Fe}-\mathrm{Nc}^{\mathrm{c}}$ ); square pyramidal (with endo ligation and intermediate $\mathrm{Fe}-\mathrm{N}^{\mathrm{c}}$ ); tetrahedral (with exo ligation and long $\mathrm{Fe}-$ $\mathrm{N}^{\mathrm{c}}$ ). Some variant Fe coordination environments are possible, such as where $\mathrm{N}^{\mathrm{c}}$ is effectively replaced by bridging $\mathrm{H}$.

(11) $\mathrm{H}$ on Fe can transfer from the endo- to exo-coordination positions with low barrier (ca $3 \mathrm{kcal}$ $\left.\mathrm{mol}^{-1}\right)$, but the barrier for the reverse process is ca $10 \mathrm{kcal} \mathrm{mol}^{-1}$.

(12) $\mathrm{H}$ can bridge a prism edge of the central $\mathrm{Fe}_{6}$ core (such as $\mathrm{Fe} 2-\mathrm{Fe} 6$ ), but not a triangle edge.

(13) FeMo-co has ample capacity to bind multiple $\mathrm{H}$ atoms and/or $\mathrm{H}_{2}$ molecules. Two $\mathrm{H}_{2}$ molecules can be bound to the one Fe atom if either the Fe- $\mathrm{N}^{c}$ bond or the Fe- $\left(\mu_{3}-\mathrm{S}\right)$ bond is severed. Structures that differ appreciably from the FeMo-co resting structure, such as exo-Fe6$\mathbf{H}_{2}$,endo-Fe6- $\mathbf{H}_{2}, \mathbf{F e} 2-\mathrm{H}-\mathrm{Fe} 6$, can be included in considerations of mechanism.

(14) FeMo-co is able to distort substantially to accommodate binding of $\mathrm{H}$ and $\mathrm{H}_{2}$, but is subject to coordinative allosteric influences. 
(15) Transfer of $\mathrm{H}$ between the endo coordination positions of two $\mathrm{Fe}$ atoms related by an edge on the central $\mathrm{Fe}_{6}$ prism is almost barrierless.

(16) $\mathrm{S}-\mathrm{H}$ to Fe-H transfers have larger barriers of 9-16 $\mathrm{kcal} \mathrm{mol}^{-1}$, with $\mathrm{S} 3 \mathrm{BH}-2$ to exo-Fe6-H being the most probable and the most exergonic of these paths for generation of $\mathrm{Fe}-\mathrm{H}$ from S-H.

(17) Association of $\mathrm{H}_{2}$ at $\mathrm{Fe}$ is generally endergonic, but the presence of endo-Fe6-H causes exoFe6- $\mathrm{H}_{2}$ association to be exergonic.

(18) Barriers for dissociation of Fe- $\mathrm{H}_{2}$ are generally ca $5 \mathrm{kcal} \mathrm{mol}^{-1}$. Transition states for Fe- $\mathrm{H}_{2}$ dissociation have Fe-H distances elongated by 0.2 to $0.6 \AA$.

(19) Additional ligands on Fe can change the dynamics for association/dissociation of $\mathrm{H}_{2}$.

(20) One very favourable process for generation of $\mathrm{H}_{2}$ is formation of exo-Fe6- $\mathrm{H}_{2}$ by transfer from $\mathrm{S} 3 \mathrm{BH}-2$ : the reaction is strongly exergonic and the barrier is small, ca $3 \mathrm{kcal} \mathrm{mol}^{-1}$.

(21) Formation of endo-Fe6- $\mathrm{H}_{2}$ by $\mathrm{H}$ transfer from S2B or from S3B has larger barriers, 12-14 kcal $\mathrm{mol}^{-1}$.

(22) $\mathrm{H}$ atoms in endo and exo positions on the same Fe atom convert exergonically to $\mathrm{H}_{2}$ in the exo position, with small (ca $3 \mathrm{kcal} \mathrm{mol}^{-1}$ ) barriers.

(23) The reverse process, also known as oxidative addition of $\mathrm{H}_{2}$, appears to be unlikely at central Fe atoms of FeMo-co.

(24) Non-dissociative atom exchange between $\mathrm{H}$ and $\mathrm{H}_{2}$ can occur readily at the one $\mathrm{Fe}$ atom.

\section{References}

(1) Van Der Sluys, L. S.; Eckert, J.; Eisenstein, O.; Hall, J. H.; Huffman, J. C.; Jackson, S. A.; Koetzle, T. F.; Kubas, G. J.; Vergamini, P. J.; Caulton, K. G. J. Am. Chem. Soc. 1990, 112, 48314841 .

(2) Gusev, D. G.; Hubener, R.; Burger, P.; Orama, O.; Berke, H. J. Am. Chem. Soc. 1997, 119, 3716-3731.

(3) Daida, E. J.; Peters, J. C. Inorg. Chem. 2004, 43, 7474-7485.

(4) Abdur-Rashid, K.; Gusev, D. G.; Lough, A. J.; Morris, R. H. Organomet. 2000, 19, 16521660 .

(5) Rod, T. H.; Norskov, J. K. J. Am. Chem. Soc. 2000, 122, 12751-12763. 